\title{
Pandemia e infodemia nas mídias: análise da desordem informacional no Twitter
}

\author{
Pandemic and infodemic on media: an analysis of the information disorder on Twitter \\ Pietra Vaz Diógenes da Silva ${ }^{1}$ \\ ${ }^{1}$ Universidade Federal de Minas Gerais, Belo Horizonte, Minas Gerais, Brasil. ORCID: http://www.orcid.org/0000-0003-4652-3897
}

Autor para correspondência/Mail to: Pietra Vaz Diógenes da Silva, pietartar@gmail.com

Recebido/Submitted: 13 de setembro de 2020; Aceito/Approved: 5 de novembro de 2020

Copyright (c) 2020 Silva. Todo o conteúdo da Revista (incluindo-se instruções, política editorial e modelos) está sob uma licença Creative Commons AtribuiçãoNãoComercial-Compartilhalgual 3.0 Não Adaptada. Ao serem publicados por esta Revista, os artigos são de livre uso em ambientes educacionais, de pesquisa e não comerciais, com atribuição de autoria obrigatória. Mais informações em http://revistas.ufpr.br/atoz/about/submissions\#tcopyrightNotice.

\begin{abstract}
Resumo
Introdução: Este artigo analisa como se desenvolve a infodemia nas mídias sociais, com enfoque no Twitter. Método: Por meio de estudo exploratório, realiza-se pesquisa bibliográfica conceitual para a compreensão de como se dá a infodemia. Parte-se, então, para análise de estudos acerca da infodemia concomitante à pandemia de COVID-19 no âmbito do Twitter, tanto em perspectiva geral quanto voltados para o Brasil. Resultados: Observa-se que não há conceito definitivo de fake news na literatura da área, embora haja elementos em comum. Nota-se que o conceito de fake news se insere nos tipos de informação que compõem a desordem informacional. Há estudos que verificam que o espalhamento de informações falsas no Twitter se dá de forma muito rápida, enquanto outros concluem que não há diferença no espalhamento de informações verdadeiras e falsas. Independentemente disso, observa-se um grande número de postagens sobre a pandemia feitas no Twitter. No cenário brasileiro, os estudos analisados apresentam divergências, mas há a constatação de que o Brasil passa pelo fenômeno da infodemia. Conclusão: A infodemia é um fenômeno perceptível no Brasil e no mundo e não deriva apenas de notícias falsas, mas sim de todo tipo de informação. As mídias sociais, inclusive o Twitter, são plataformas propícias para a circulação rápida de informações. É importante o desenvolvimento de mais pesquisas nacionais, desenvolvidas em consonância com os acontecimentos locais, para a consolidação de uma análise da infodemia no Brasil que capte as peculiaridades do cenário brasileiro
\end{abstract}

Palavras-chave: COVID-19; Infodemia; Desordem informacional; Fake News; Twitter.

\begin{abstract}
Introduction: This paper analyzes how infodemic occurs on social media, focusing on Twitter. Method: Through an exploratory study, we carry out bibliographic research to understand basic concepts that set an infodemic. Then, we proceed to analyze studies about the infodemic developed during the COVID-19 pandemic on Twitter, both from a general perspective and focused on Brazil. Results: We notice that there is no definitive concept of fake news in scientific literature, although there are elements in common. Fake news fits one of the concepts that make part of information disorder. Some studies notice that the spreading of false information on Twitter occurs rapidly, but others see no difference in the spreading of true and false information. Regardless of those results, there is a large number of posts on the pandemic on Twitter. In the Brazilian scenario, results show divergences, but they agree that Brazil is indeed experiencing an infodemic. Conclusions: Infodemic is a noticeable phenomenon around the world and also in Brazil. It is not due only to fake news, but to all types of information. Social media, including Twitter, are platforms that allow information to spread quickly. Brazilian studies, developed in line with local events, would be relevant to bring up an analysis that considers all the peculiarities of the country's scenario.
\end{abstract}

Keywords: COVID-1; Infodemic; Information disorder; Fake News; Twitter.

\section{INTRODUÇÃO}

Atualmente, vive-se em conjunturas cujas fronteiras são de difícil definição. Se outrora a comercialização da imprensa turvou a delimitação entre as esferas pública e privada(Habermas, 2014), hoje já não há diferença significativa entre o que ocorre no plano real e no virtual, sendo que ambos se impactam mutuamente. Desde a década de 1990, os limites entre as mídias estabelecidas e emergentes têm sido cada vez mais rompidos (Briggs \& Burke, 2006), consolidando a multimedialidade.

De acordo com Briggs e Burke (2006), essa tendência noventista atingiu diversos âmbitos: acontecimentos locais tornaram-se globais; hábito e aprendizagem se confundiram; disciplinas independentes passaram a ser estudadas em suas transversalidades - História, Sociologia e Direito, por exemplo, tiveram suas semelhanças reconhecidas e exploradas, na valorização de suas interseções epistemológicas em detrimento das divisões cartesianas do saber (Santos, 2008).

Observando a dinâmica dessas definições, nota-se um amálgama que tem ganhado notoriedade, o qual envolve mídia e saúde - ou, mais especificamente, mídia e vírus. A origem da paridade entre esses dois campos não é recente. Remontando às origens da comunicação, o escritor beat, William Burroughs, teorizou em seu ensaio "A revolução eletrônica", publicado originalmente em 1970, que "a palavra escrita foi literalmente um vírus que tornou possível a palavra falada. A palavra não tem sido reconhecida como vírus porque atingiu um estágio de simbiose estável com o hospedeiro" (Burroughs, 1994, p. 21). 
Já sob outra perspectiva, a palavra "vírus" passou a ser adotada por jornalistas e técnicos ao tratar da então inovadora área da informática. Acerca dos vírus de computador, observam Briggs e Burke (2006, p. 313):

Cada vírus tinha sua própria "assinatura", e embora fosse possível proteger o equipamento com um programa antivírus, não havia garantia total contra a infecção. Os paralelos com a saúde pareciam pertinentes, talvez apenas porque houvesse uma preocupação crescente, durante esses anos, tanto na mídia quanto entre os políticos, com a saúde privada e pública [...].

A palavra "vírus" no contexto em questão tornou-se de comum uso. O Dicionário Michaelis, disponível online, incorporou tal significado, de forma que apresenta o termo tanto como "organismo infeccioso diminuto sem capacidade metabólica independente" (Michaelis, 2020) quanto como "programa fraudulento que se instala em computadores que pode causar vários tipos de danos, alguns irreparáveis, como a paralisação total da máquina" (Michaelis, 2020), além de outras definições.

A pandemia de COVID-19 levou o primeiro significado do termo para um lugar de destaque em notícias e diálogos de 2020. E, mais do que isso, acentuou de outra forma a relação entre mídia e vírus. Isso porque, juntamente com a pandemia, instaurou-se também uma infodemia. Esta foi definida pela Organização Pan-Americana da Saúde (OPAS), que é uma divisão da Organização Mundial da Saúde (OMS), como

[...] um excesso de informações, algumas precisas e outras não, que tornam difícil encontrar fontes idôneas e orientações confiáveis quando se precisa. A palavra infodemia se refere a um grande aumento no volume de informações associadas a um assunto específico, que podem se multiplicar exponencialmente em pouco tempo devido a um evento específico, como a pandemia atual. Nessa situação, surgem rumores e desinformação, além da manipulação de informações com intenção duvidosa. Na era da informação, esse fenômeno é amplificado pelas redes sociais e se alastra mais rapidamente, como um vírus. (Organização Pan-Americana da Saúde, 2020, p. 2)

Nesse sentido, e considerando a indissociação entre os ambientes real e virtual, faz-se necessária a compreensão do panorama do combate à pandemia por meio do ataque à infodemia. E, sendo as mídias sociais expoentes da nova mídia, em contraposição às mídias de massa (McQuail, de Jesus, \& Ponte, 2003), volta-se a atenção para esses meios que se encontram entre o estabelecido e o experimental, sendo já consolidados o suficiente para gerar grande impacto - ao menos no cenário brasileiro -, porém dotados de individualidades e interatividades que dificultam a análise das informações propagadas.

\section{METODOLOGIA}

O presente artigo tem como problema a seguinte questão: como ocorre a infodemia no Twitter durante a pandemia de COVID-19 em 2020? Com base nisso, a análise é feita de forma geral e também com enfoque no cenário brasileiro, buscando compreender no que consiste a infodemia e como ela ocorre no Twitter. Optou-se por restringir o estudo tão somente para tal mídia social, não apenas para tornar o trabalho mais exequível, mas também pelo fato de o Twitter ter sido indicado por Castaldi et al. (2020) como ideal para avaliar a carga dinâmica da ansiedade social na Internet. Isso se dá porque as postagens feitas no Twitter, denominadas tuítes, representam as necessidades mais urgentes de comunicação, enquanto outras redes, como o Facebook, possuem mais espaço para debates, o que leva a respostas mais lentas. É realizada, assim, uma pesquisa bibliográfica por meio de um estudo exploratório, conforme apresentado por Gil (2008).

Inicialmente, realiza-se uma revisão de literatura, de forma a criar um arcabouço teórico aproximativo acerca dos fenômenos de des-informação. Nesse sentido, a busca por bibliografia foi feita nas plataformas Scielo e Directory of Open Access Journals (DOAJ), por meio dos termos de busca "fake news", "pós-verdade", "desordem informacional", e "desordem da informação". Utilizando os mesmos termos, também foram consultados os repositórios de produção acadêmica de três instituições de ensino brasileiras, quais sejam: Universidade Federal de Minas Gerais (UFMG), Universidade Federal da Bahia (UFBA), Universidade de São Paulo (USP). Não houve delimitação temporal para os resultados analisados, tendo sido selecionados os textos mais pertinentes para o trabalho, nas línguas portuguesa e inglesa, de forma a construir um panorama do desenvolvimento e da compreensão atual dos termos buscados. Ainda, sem prejuízo da utilização das publicações científicas selecionadas, também foram considerados livros com pertinência temática, incluindo tanto obras cuja leitura já havia sido realizada pelo(s) autor(es) previamente, quanto títulos descobertos a partir da leitura das obras analisadas no momento inicial da pesquisa.

Posteriormente, a busca voltou-se para a infodemia que acompanhou a pandemia de COVID-19, o que consequentemente restringiu os resultados para publicações de 2020. Foram consultadas as plataformas Scielo, DOAJ, ScienceDirect da editora Elsevier, Nature e Science, tendo sido utilizados os termos "infodemia"; "infodemia" e "pandemia"; "infodemic"; e "infodemic" e "pandemic". A partir da leitura dos resultados, foram selecionados os trabalhos que melhor auxiliaram na identificação de possíveis convergências e divergências entre os dados sobre o Twitter no momento da pandemia e os estudos sobre os conceitos previamente apresentados. Para tanto, destacam-se as definições conceituais propostas por Wardle e Derakhshan (2017, 2020), bem como, conforme 
será demonstrado, o "Covid19 Infodemic Observatory" (De Domenico, Gallotti, Sacco, Castaldo, \& Valle, 2020), a nível global, e o estudo de caso voltado para o Brasil realizado por Recuero e Soares (2020), denominado "O Discurso Desinformativo sobre a Cura do COVID-19 no Twitter".

\section{FAKE NEWS}

A ascensão das novas mídias, no início da era da Internet e dos computadores pessoais, provocou otimismo nos entusiastas da tecnologia. O então Professor do Instituto de Tecnologia de Massachusetts, Ithiel Pool, tomava as novas ferramentas como garantia de mais acesso a informações, mais conhecimento e mais liberdade de expressão (Pool, 1983). Em meio a altas expectativas, o Professor constatou que "a tecnologia, no entanto, dita a forma da batalha, mas não os seus resultados" (Pool, 1983, p. 251).

Tomando isso como base, de fato, é possível compreender a informação como a forma da "batalha" que é travada presentemente. Torna-se pertinente evocar o termo fake news, que se refere a "notícias ou informações falsas que são apresentadas de uma maneira que parece ser verdadeira" (Okano, 2020, p. 51). Lazer et al. (2018, p. 1094) em um estudo amplamente citado, definem fake news como "informação fabricada que imita conteúdo de mídia jornalista em sua forma, mas não em seu processo organizacional ou em sua intenção", sendo a intenção frisada como um elemento definidor de fake news ao longo do texto. Entretanto, como frisado por Cardoso (2019), o conceito ainda não é dotado de consenso entre pesquisadores.

Observa-se a definição de Allcott e Gentzkow (2017) de que as fake news são sempre produtos intencionais, cuja falsidade do conteúdo é passível de verificação e podem enganar seus receptores. Esse entendimento exclui itens como erros não intencionais em reportagens; rumores sem origem certa; teorias da conspiração; sátiras que dificilmente serão interpretadas como verdadeiras; declarações falsas feitas por políticos; e notícias tendenciosas, mas não essencialmente falsas.

Dourado (2019) concorda com os autores e compreende que fake news sempre são criadas em prol de algum interesse, independentemente de seu formato - texto, vídeo, imagem etc. - sendo um fenômeno intimamente conectado à esfera política, sendo que "fake news não devem ser confundidas com comentários, opiniões, obras claramente de ficção, memes e sátiras políticas baseadas em mentiras, intolerância, sectarismo e teorias da conspiração [...] no cerne dessas peças, encontra-se a base factual e o aspecto noticioso" (Dourado, 2019, p. 57).

Entende-se aqui, porém, que essa limitação é um tanto imprecisa. Muitas questões podem ser suscitadas. Exemplifica-se: o que indicaria a probabilidade de uma sátira ser interpretada como tal ou como um fato? Qual a diferença prática entre uma notícia tendenciosa e uma falsa, especialmente se for considerado que a intenção e o resultado - de ambas é enganar? Ainda, o que pode ser afirmado como claramente ficcional considerando em tempos de pós-verdade - isto é, quando emoções e crenças pessoais são mais importantes para a opinião pública do que os fatos objetivos (Oxford Languages, 2020)?

Persily (2017), evitando semelhante imbróglio, propôs uma classificação de fake news em quatro categorias: sátiras; notícias falsas com fins lucrativos; propaganda política; e reportagens imprudentes. O autor concorda, no entanto, que tomar todas as declarações falsas postadas na Internet como fake news não é uma forma eficiente de descrever tal fenômeno social. Por sua vez, Sintra (2019) afirma que fake news, em sua origem, referia-se a conteúdos como paródias e sátiras, mas que atualmente possui outro sentido: o de histórias falsas, com objetivos específicos, que se propagam pelas mídias sociais.

Para a caracterização da infodemia, porém, parece ser necessário levar em consideração todas as partículas do "tsunami de informação" (Zarocostas, 2020, p. 676) que se formou concomitantemente à pandemia. O já mencionado folheto informativo da OPAS indica que "a desinformação se expande no mesmo ritmo que a produção de conteúdo, e as vias de distribuição se multiplicam. Assim, a própria infodemia acelera e perpetua a desinformação" (Organização Pan-Americana da Saúde, 2020, p. 3). O entendimento de que nem todo conteúdo inexato pode ser considerado, a rigor, como fake news leva à necessidade de construir uma análise por meio de outros conceitos.

\section{DESORDEM INFORMACIONAL}

Grandes quantidades de informação são geradas em curto prazo, em processos que se repetem a todo tempo, gerando o que Marchiori (2002) conceitua como o paradoxo do excesso de informações. Se na década de 1980 já se percebia o "registro de conhecimento em um fluxo sem precedentes" (Pool, 1983, p. 226), atualmente a produção de informação cresce continuamente, sendo que os esforços aplicados 'à chamada 'gestão do conhecimento' [aumentam] ainda mais o fluxo vertical e horizontal de dados e informações" (Marchiori, 2002, p. 78).

Tamanho fluxo, enfatiza-se, é mensurado por sua quantidade, não por sua qualidade. Byung-Chul Han (2018) compreende que o consumo de maiores quantidades de informação não é necessariamente proporcional à qualidade das decisões que se toma, nem da lucidez que se alcança. Ainda que se considere que a qualidade da informação 
pode torná-la um instrumento de educação ou de deseducação (Coelho, 2018), essa distinção perde a relevância. Isto é, as informações são tantas que, em detrimento do seu objetivo de comunicar e instruir, passam a ser apenas acúmulos, cargas vazias que não acrescentam no conhecimento de quem as encontra. É possível até mesmo questionar o próprio uso do termo "informação", trocando-o por "conteúdo" (Dourado, 2019), de forma a explicitar mais tal ideia.

Isso, somado às inúmeras possibilidades facilitadas de expressão nas mídias sociais e à ausência de mediação do conteúdo publicado - como se vê ainda nas mídias de massa -, faz com que toda opinião, por mais infundada que seja, tenha espaço. Em verdade, Han (2018) vê que o meio digital criou um novo formato de massa, chamada por ele de "enxame". Diferentemente das abelhas, o enxame digital não é coordenado, mas sim um agrupamento de várias singularidades isoladas; porém, igualmente às abelhas, o enxame digital produz inúmeros ruídos desconexos, muitas vezes incoerentes, que refletem não o todo, mas o próprio sujeito.

Os ruídos - que podem ser opiniões publicadas em forma de post nas redes - podem provocar danos não intencionais. Munidos de boa-fé, muitos usuários compartilharam supostos tratamentos, curas ou práticas preventivas para a COVID-19, como a ingestão de bebidas cítricas e o gargarejo com água morna (Lima et al., 2020). Essa confusão de informações sem base científica não pode ser totalmente encaixada na definição comum de fake news, mas se coaduna com a desordem informacional apresentada por Wardle e Derakhshan (2017, 2020).

Destaca-se que a expressão information disorder, amplamente utilizada na língua inglesa, já foi traduzida tanto como "desordem informativa" quanto como "desordem informacional" em textos na língua portuguesa. Opta-se pelo uso da segunda tradução por remeter ao capitalismo informacional descrito por Castells (1999), em que a indústria da informação passa a ser um definidor do modo de produção capitalista.

O conceito engloba três formas de desordem informacional, que são mis-information, dis-information e malinformation. Dourado (2019) traduziu os termos como, respectivamente: informação errada, desinformação e informação maliciosa. Lima et al. (2020) entendem que os dois primeiros termos equivalem a "desinformação" na língua portuguesa, embora na definição de Wardle e Derakhshan (2017) possuam significados diferentes; enquanto o último não possui palavra equivalente. Entende-se aqui da mesma forma como Lima et al. (2020) e opta-se por não traduzir os termos para evitar possível confusão entre uma categoria com um substantivo adjetivado. Tem-se que:

Mis-information é quando a informação falsa é compartilhada, mas não há intenção de dano. Dis-information é quando a informação falsa é compartilhada com o objetivo de causar dano. Malinformation é quando a informação verdadeira é compartilhada para causar dano, e ocorre geralmente levando a público a informação que deveria se ater à esfera privada. (Wardle \& Derakhshan, 2017, p. 20)

De forma a visualizar a relação entre os conceitos, observa-se a Figura 1.

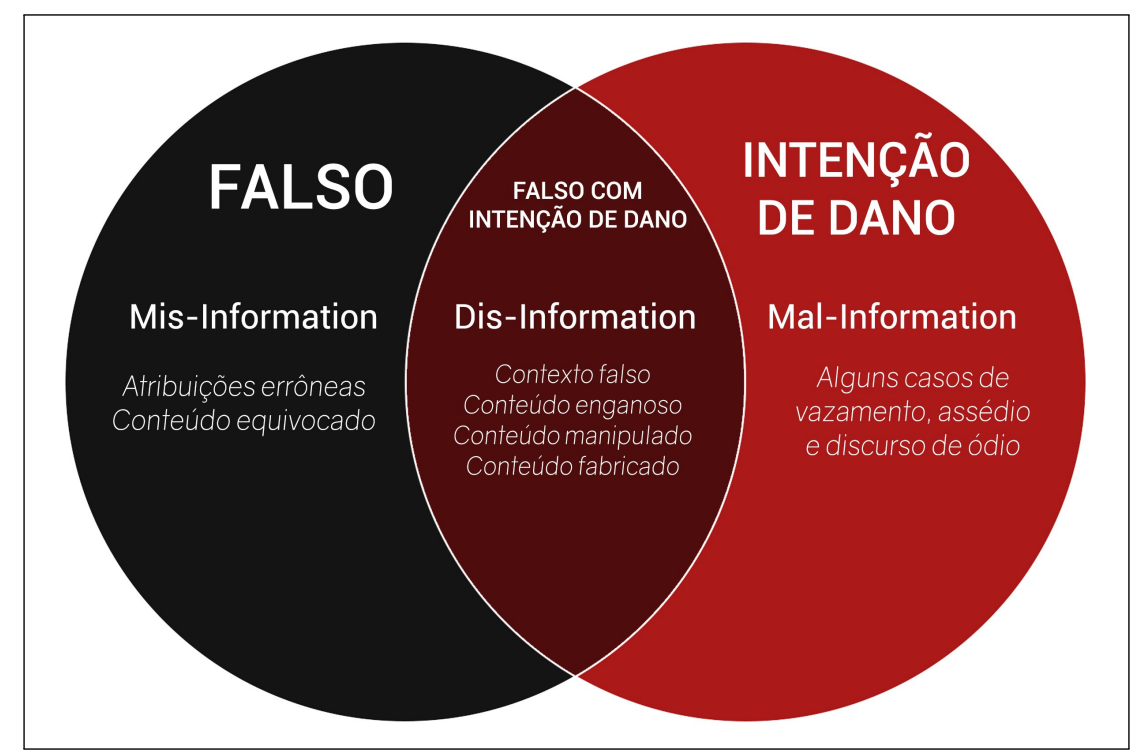

Figura 1. Diagrama com os conceitos da desordem informacional.

Fonte: elaborado pelo(s) autor(es) a partir de Wardle e Derakhshan (2020, p. 44)

É interessante perceber que o diagrama acima reproduzido, quando apresentado pelos autores pela primeira vez, listava como mal-information apenas "vazamentos, assédio, discurso de ódio" (Wardle \& Derakhshan, 2017, p. 20); e na segunda vez houve uma atualização para "(alguns) vazamentos, (alguns) assédios, (alguns) discursos de ódio" (Wardle \& Derakhshan, 2020, p. 44). Entende-se, com isso, que nem toda denúncia verdadeira de assédio, 
por exemplo, é feita estrategicamente na intenção de causar dano ao assediador; há casos em que tais episódios são levados a público para que sejam tratados na forma da lei.

Nota-se, enfim, que a desordem informacional abrange uma gama mais ampla de tipos de informação. Para que ela seja classificada como mis-information, dis-information ou mal-information, é preciso que se observe o agente que criou, produziu e distribuiu a informação, bem como sua motivação; a informação compartilhada, seu formato e suas características; e o receptor, com atenção a como a informação foi interpretada e, caso tenha tomado alguma atitude a respeito dela, qual foi a atitude em questão (Wardle \& Derakhshan, 2017)).

Além dos elementos, os autores também elencam as fases da informação em meio ao ciclo da desordem informacional. A primeira delas é a criação, em que a informação é concebida; seguida pela produção, em que a informação é transformada em produto de mídia; e a última é a distribuição, na qual a informação é disseminada (Wardle \& Derakhshan, 2017). Nota-se que, uma vez que a informação se torna um produto, a segunda e a terceira fases passam a se repetir, podendo a informação ser incessantemente (re)produzida e novamente distribuída (Figura 2).

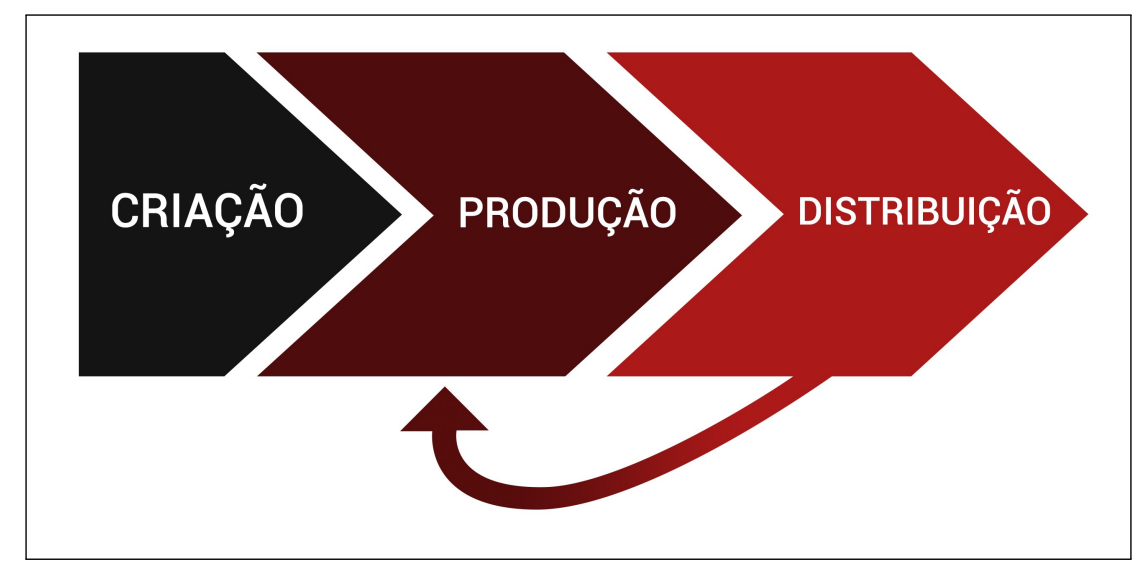

Figura 2. Fases da informação na desordem informacional.

Fonte: elaborado pelo(s) autor(es) a partir de (Wardle \& Derakhshan, 2017, p. 22)

A instauração dessa dinâmica remete ao entendimento de que, em uma realidade composta pelo digital, já não há diferença entre o que é original e o que é cópia, sendo que unidade, identidade e localização não mais importam (Lévy, 1996). Wardle e Derakhshan (2017), conscientes dessa complexidade, acreditam que o termo fake news é insuficiente para tratar do fenômeno; para além disso, entendem que o termo deve ser evitado. Conforme os autores, a expressão foi banalizada, tendo sido recorrentemente utilizada em situações problemáticas - como ataques à imprensa, realizados por figuras políticas, que chamam de fake news quaisquer notícias que os desfavoreçam.

Com efeito, notou-se que as definições mais abrangentes de fake news na literatura recente não abarca por completo o fenômeno informacional que se compreende como a infodemia. No entanto, tem-se a impressão de que as fake news são uma das variedades de informação que compõem a desordem informacional.

A conduta de receber uma informação e repassá-la sem checar sua veracidade, de forma que o indivíduo passa a ser um desinformador sem ter a intenção de sê-lo (Lima et al., 2020), é contemplada na definição de desordem informacional, mas não na de fake news, pois a compreensão mais aceita é a de que o elemento intenção é essencial. Ainda assim, na circulação de uma fake news deliberadamente criada para levar ao engano, diversos sujeitos - inclusive os enganados - podem propagá-la sem a intenção de enganar.

Dessa forma, em detrimento de substituir o uso do termo fake news pelo termo desordem informacional, entende-se que são fenômenos diferentes que coexistem - estando, aliás, um inserido no outro: fake news parece adequar-se à classificação de dis-information. E assim se observa que o ambiente virtual é propício para a disseminação de toda sorte de informação: mentiras, verdades, e tudo o que se encontra entre os dois extremos.

\section{A INFODEMIA NO TWITTER}

O Twitter se define como "o lugar certo para saber mais sobre o que está acontecendo no mundo e sobre o que as pessoas estão falando agora" (Twitter, 2020b). Em tempos de pandemia, isso se fez notório: 249 milhões de usuários publicaram sobre COVID-19 entre janeiro e maio de 2020 (Larson, 2020). Ressalta-se que esse dado não mostra a quantidade de tuítes acerca do assunto feitos no período, mas sim quantos usuários tuitaram sobre o tema, de forma que cada usuário pode ter tuitado mais de uma vez.

Entre 27 de janeiro e 14 de fevereiro, foram publicados 1.187.482 tuítes, partindo de 390.866 usuários diferentes, contendo os termos "coronavirus" ou "ncov" ou "coronavirusoutbreak" ou "wuhan" ou "iamnotavirus" (Vosoughi, 
Roy, \& Aral, 2018, p. 10-11). O folheto informativo sobre a infodemia da OPAS assevera que no mês de março foram postados aproximadamente 550 milhões de tuítes contendo "coronavirus" ou "corona virus" ou "covid19" ou "covid-19" ou "covid19" ou "pandemic", sendo que $6 \%$ das postagens foram feitas no Brasil (Organização Pan-Americana da Saúde, 2020, p. 2)

Bridgman et al. (2020) concluíram que o uso de mídias sociais está proporcionalmente relacionado com percepções erradas a respeito da COVID-19 e que estas, por sua vez, são proporcionalmente relacionadas com o não cumprimento das medidas de distanciamento social. Apesar de os dados utilizados no estudo serem referentes ao contexto canadense, e os tuítes utilizados estarem apenas na língua inglesa, os pesquisadores compreendem que a dinâmica é a mesma em qualquer local: indivíduos que consomem informações de plataformas em que há mais desinformação - e, neste ponto, pode ser que a plataforma não seja o Twitter em outros locais - percebem a pandemia de forma errônea, e isso leva a menos percepção de risco.

É importante considerar que todo tuíte é passível de ampla repercussão e que informações falsas tendem a se espalhar mais rapidamente do que as verdadeiras (Vosoughi et al., 2018). A dinâmica do compartilhamento de informações no Twitter ocorre da seguinte forma:

A cascata de rumores começa no Twitter quando um usuário faz uma afirmação sobre um tópico em um tuíte, que pode incluir texto escrito, fotos ou links para artigos. Então, outros propagam o rumor retuitando-o [isto é, repostando o primeiro tuíte em seus perfis]. O processo de difusão de um rumor pode ser caracterizado como tendo uma ou mais dessas cascatas, que definimos como instâncias de um padrão de disseminação de rumor que exibe uma cadeia ininterrupta de retuítes com uma origem comum [o primeiro tuíte, no topo da cascata]. Por exemplo, um indivíduo pode iniciar uma cascata de rumores ao tuitar uma história ou afirmação, e outro indivíduo pode iniciar de forma independente uma segunda cascata do mesmo rumor (relativo à mesma história ou afirmação) que é completamente independente da primeira cascata, mas que se refere à mesma história ou afirmação. Se ambas as cascatas permanecerem independentes, representam duas cascatas do mesmo rumor. (Vosoughi et al., 2018, p. 1146)

Observa-se que o termo "rumor" abrange os tipos de informação falsa previamente definidos como mis-information e dis-information. Em seu estudo sobre o desenvolvimento das cascatas, Vosoughi et al. (2018) analisaram aproximadamente 126 mil cascatas investigadas por seis organizações de verificação de fatos.

Na pesquisa em questão, os autores constataram que informações verdadeiras levaram cerca de seis vezes mais tempo do que informações falsas para atingir 1.500 usuários. Ademais, as informações falsas se espalharam com mais profundidade nas cascatas - isto é, foram mais retuitadas: informações verdadeiras levaram cerca de vinte vezes mais tempo do que as falsas para atingir dez retuítes. Nenhuma informação verdadeira espalhou-se com uma profundidade superior a dez retuítes, e informações falsas atingiram dezenove retuítes cerca de dez vezes mais rápido do que informações verdadeiras atingiram dez retuítes (Vosoughi et al., 2018).

No entanto, em um estudo acerca da infodemia relativa à pandemia de COVID-19 nas mídias Twitter, YouTube, Gab e Reddit, concluiu-se que os padrões de espalhamento de informações por eles classificadas como confiáveis e questionáveis no Twitter não apresentam diferenças significativas (Cinelli et al., 2020). O engajamento compreendido como a interação média que cada tuíte recebe de outros usuários - no Twitter é o mais alto das mídias analisadas. Ao mesmo tempo, o Twitter também demonstrou ser a mídia mais neutra entre elas. Isso significa que o funcionamento da própria plataforma confere tratamento similar a informações confiáveis e questionáveis (com coeficiente de amplificação de notícias questionáveis 0,97). Outras redes apresentaram menor tendência a aumentar o impacto de informações questionáveis, como o Youtube $(0,35)$ e o Reddit $(0,55)$. O Gab, por sua vez, amplifica significativamente tal impacto (3,9) (Cinelli et al., 2020).

De Domenico et al. (2020), do departamento Complex Multilayer Networks da Fundação Bruno Kessler, na Itália, criaram um observatório online da infodemia, com foco no Twitter, chamado Covid19 Infodemic Observatory ou "covid19obs". Por meio de técnicas de machine learning, são analisados 4,7 milhões de tuítes com referência a COVID-19 por dia, coletando dados acerca da carga emocional dos tuítes, com base no léxico; da natureza de quem tuita, ou seja, se são humanos ou bots; e da confiabilidade das informações, com base nas fontes às quais a informação se vincula (De Domenico et al., 2020).

A classificação das fontes como confiáveis ou questionáveis, por sua vez, parte da atribuição feita por nove grupos de verificação de fatos, independentes do grupo do observatório. As fontes, então, são inseridas em grupos conforme sua natureza: sites de ciência e de mídias convencionais - exemplos são links para revistas científicas e portais de notícias conhecidos e estabelecidos - são tomados como fontes confiáveis; ao passo que sátiras, clickbaits - que são portais conhecidos por manchetes propositalmente distorcidas, com o intuito de gerar acessos -, conteúdo político, notícias falsas, teorias da conspiração e pseudociência são classificadas como fontes questionáveis. Há também a categoria "obscura" (shadow), composta por links quebrados ou que não levam a nenhum site, e a categoria "outros", em que se inserem os conteúdos não passíveis de verificação automática, como vídeos. As duas últimas categorias são descartadas da análise (De Domenico et al., 2020). 
No início de setembro de 2020, as estatísticas globais eram de que, de 459,9 milhões de tuítes, $57,7 \%$ foram postados por pessoas e $42.3 \%$ por bots; e $71,1 \%$ dos tuítes continham informações confiáveis, enquanto $28,9 \%$ traziam informações questionáveis (De Domenico et al., 2020). Apesar de os estudos ora verificados não representarem a totalidade do fenômeno da infodemia no Twitter, é notável que a análise de apenas algumas das suas facetas já demonstra o grande fluxo global de informações, confiáveis ou não, referentes à pandemia.

\section{O CENÁRIO BRASILEIRO}

De acordo com o observatório, o Brasil possui uma média de 77.276,6 tuítes analisados por dia, dos quais $62,89 \%$ são confiáveis. O índice de infodemia no Brasil, em uma escala de 0 a 1, é em média 0,2460. Na Figura 3, é possível observar que a infodemia no país, conforme os critérios apresentados, aumentou especialmente a partir do mês de abril, tendo como pico o dia 01 de junho de 2020 (em que o índice atingiu 0,58). Na Figura 4, observam-se os níveis de informações classificadas como confiáveis e questionáveis.

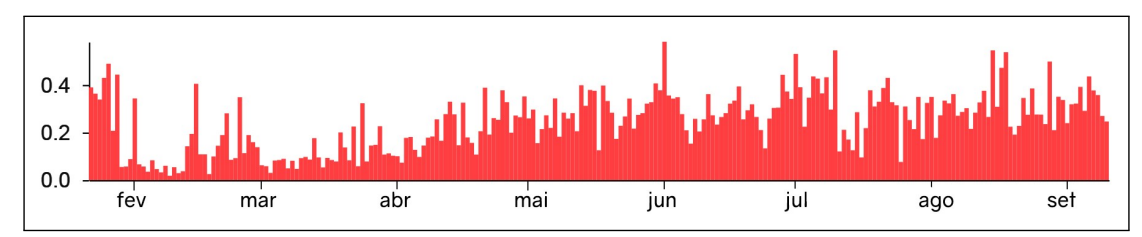

Figura 3. Índice de infodemia no Twitter no Brasil, em escala de 0 a 1, de 22 de janeiro de 2020 a 09 de setembro de 2020. Fonte: adaptado pelo(s) autor(es) a partir do Covid19 Infodemic Observatory (De Domenico et al., 2020)

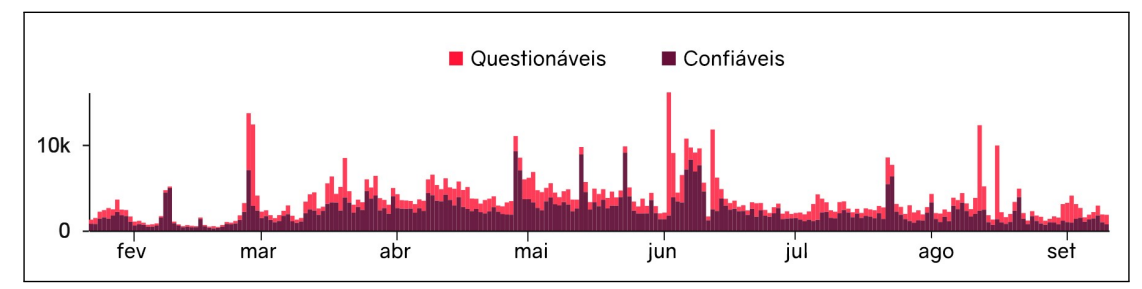

Figura 4. Classificação das informações do Twitter no Brasil analisadas pelo Covid19 Infodemic Observatory, de 22 de janeiro de 2020 a 09 de setembro de 2020.

Fonte: adaptado pelo(s) autor(es) a partir do Covid19 Infodemic Observatory (De Domenico et al., 2020)

Entretanto, é necessário considerar ainda alguns fatores. Evidencia-se primeiramente que, embora os dados apresentados sejam relevantes, não representam a totalidade do cenário nacional. De acordo com relatório do Instituto Reuters, elaborado por Newman, Fletcher, Kalogeropoulos, e Nielsen (2020), o Twitter é a sexta mídia social mais utilizada para se informar pelos usuários brasileiros conectados, sendo que $15 \%$ destes usam a rede para tal fim. A terceira mídia mais utilizada pelos brasileiros para se informar é o YouTube (42\%) (Newman et al., 2020), e viu-se que conteúdos em vídeo são descartados da análise do Covid19 Infodemic Observatory, pois o formato não pode ser analisado automaticamente. Em dados coletados no portal referentes ao dia 09 de setembro de 2020, foi possível constatar que, de um total de 37.579 tuítes feitos no dia, 4.421 pertencem ao grupo "outros" e não são sequer considerados na análise, havendo então uma lacuna nos dados.

Ademais, há o problema da forma como ocorre a repercussão de fatos relevantes por meio dos perfis de veículos da mídia de massa nas mídias sociais - como o da Folha de São Paulo ou do Estadão, que são veículos tradicionais da mídia, mas repercutem em seus perfis nas redes. Os portais são considerados fontes confiáveis conforme os critérios estabelecidos pelo Covid19 Infodemic Observatory, porém tem sido comum a divulgação de fatos de forma acrítica. Importantes figuras políticas do Brasil, como o próprio presidente da república, têm adotado um discurso anticientífico (Lima et al., Recuero e Soares, 2020). A própria rede social Twitter deletou tuítes postados na conta do presidente Jair Bolsonaro, pois tratava-se de conteúdo falso com potencial de causar danos aos indivíduos que buscam se informar naquela conta oficial (Ball \& Maxmen, 2020).

A divulgação de falas e pronunciamentos cujos teores estão em desacordo com estudos científicos, não raramente, é feita de forma que não reforça o caráter incorreto das informações, mas sim de maneira que apenas ecoa as informações pronunciadas sem respaldo. Considerando ainda que cerca de $59 \%$ dos artigos de portais de notícia compartilhados no Twitter não são previamente lidos (Gabielkov, Ramachandran, Chaintreau, \& Legout, 2016), as manchetes reproduzindo citações descontextualizadas acabam contribuindo para a desordem informacional.

O Twitter, entretanto, tem feito um esforço para o combate à expansão de conteúdo falso. Um dos mecanismos introduzidos pela rede no Brasil e no mundo, disponível desde 10 de junho de 2020 na versão para celular da rede, aparece na tela do usuário quando este clica nos ícones para retuitar ou comentar um tuíte contendo uma notícia. Trata-se de um prompt perguntando se o usuário gostaria de ler o artigo antes de realizar a ação. A 
página "Como retweetar" da central de ajuda do Twitter atesta: "Acreditamos que isso ajuda na contextualização e reduz a disseminação não intencional de informações enganosas no Twitter" (Twitter, 2020a).

Em 24 de setembro de 2020, o perfil oficial de comunicação do Twitter na própria mídia compartilhou alguns dados: aumentou em 33\% o número de usuários abrindo páginas de notícias antes de retuitá-los; os usuários, de forma geral, passaram a abrir mais páginas de notícias com uma frequência de 40\% depois que se depararam com o prompt; e alguns usuários (o dado não foi quantificado pela rede) não retuitaram a notícia depois que abriram a página (Twitter Comms, 2020). O mecanismo, porém, ainda está sendo ajustado e não aparece todas as vezes para todos os usuários.

De fato, ler a notícia para além da manchete é uma conduta importante para conter o conteúdo falso que alimenta a desordem informacional. O editorial da revista Lancet Infectious Diseases de agosto de 2020 assevera:

Essa falta de comunicação não é ajudada pela mídia de massa, que muitas vezes é culpada de favorecer reportagens rápidas e sensacionalistas, em detrimento de mensagens científicas cuidadosamente formuladas com uma interpretação equilibrada. O resultado é a erosão da confiança pública e uma sensação de desamparo, as condições perfeitas para a disseminação de desinformação prejudicial que inicia um círculo vicioso (Lancet Infectious Diseases, 2020, p. 875)

Recuero e Soares (2020), em estudo voltado para os discursos acerca da pandemia no Brasil feitos no Twitter, identificaram que declarações de Bolsonaro tiveram impacto no volume da desordem informacional. A pesquisa mostra que, antes de pronunciamentos sem embasamento científico sobre a "cura" da COVID-19 por meio da hidroxicloroquina, as principais mensagens que circulavam no Twitter eram no sentido de desmentir falsas informações. Já após as falas, houve maior visibilidade de informações falsas - tanto mis-informations, chamadas pelos autores de "enquadramento enganoso", e dis-informations, denominadas "conteúdo fabricado". As análises foram feitas em três períodos diferentes, sendo que dois deles se deram logo após falas do presidente contendo informações falsas. Nestes dois períodos, a desordem informacional aumentou em comparação ao período sem fala prévia por parte do presidente (Recuero \& Soares, 2020).

Há impossibilidade de cruzar os dados de Recuero e Soares (2020) com os coletados pelo Covid19 Infodemic Observatory de De Domenico et al. (2020). Os indicadores e as variáveis utilizados nos trabalhos são diferentes, bem como os critérios para seleção de tuítes analisados. Nota-se também que os resultados não apresentaram correspondência. O aumento de desordem informacional percebida por Recuero e Soares nos períodos não se evidencia na análise do Covid19 Infodemic Observatory.

Ainda que não seja possível realizar o cruzamento dos dados, em razão de suas variedades metodológicas, pode-se visualizar informações das referidas pesquisas nas tabelas a seguir (Tabela 1, Tabela 2):

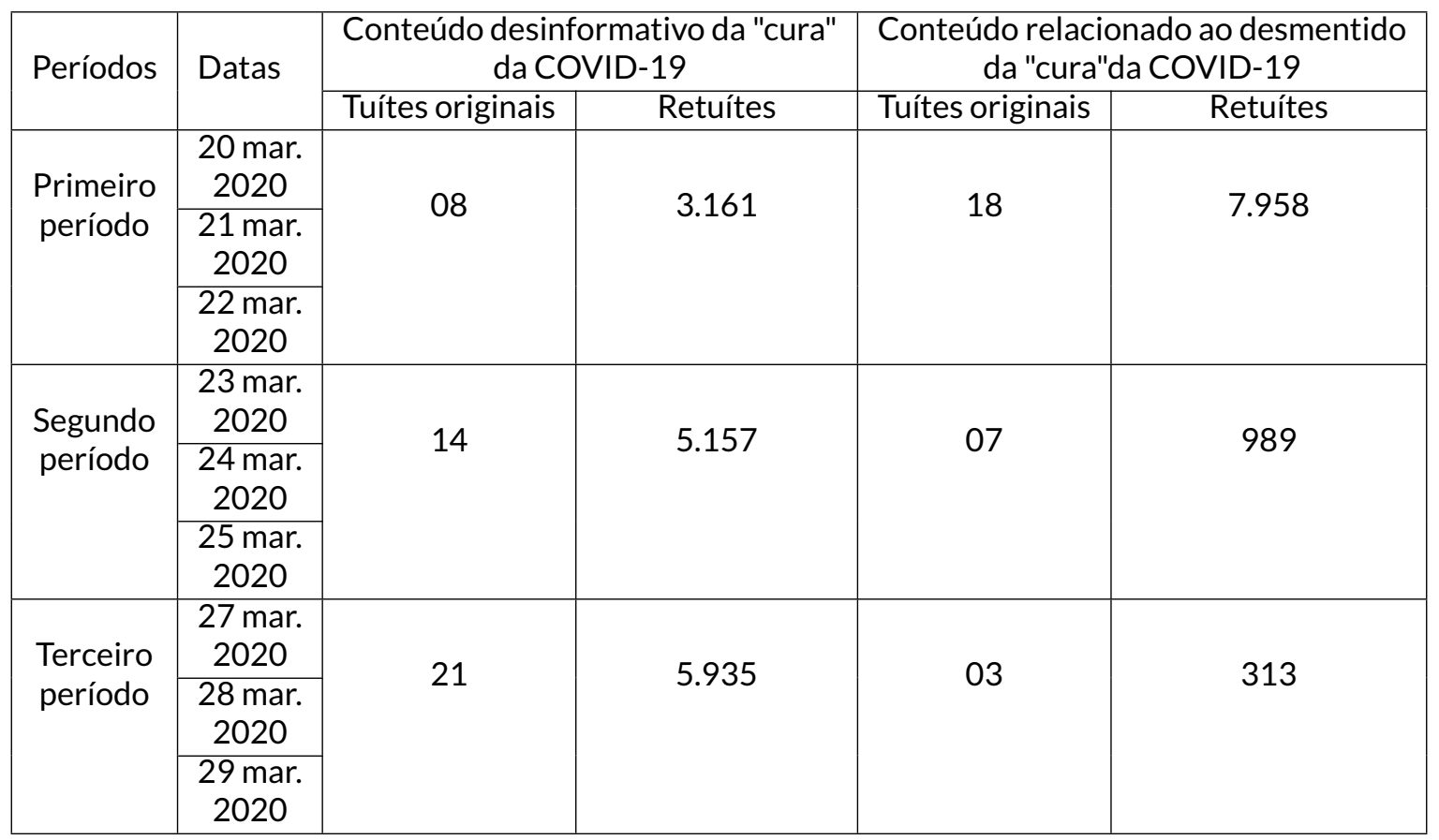

Tabela 1. Dados dos tuítes analisados por Recuero e Soares (2020)

Fonte: Recuero e Soares (2020, p. 12) 


\begin{tabular}{|c|c|c|c|}
\hline $\begin{array}{l}\text { Períodos (conforme a divisão } \\
\text { de Recuero \& Soares (2020)) }\end{array}$ & Datas & $\begin{array}{c}\text { Confiabilidade (em quantidades } \\
\text { de tuítes) }\end{array}$ & Índice de infodemia \\
\hline \multirow{3}{*}{ Primeiro período } & 20 mar. 2020 & $\begin{array}{l}\text { Q: } 4,61 \mathrm{mil} \\
\text { C: } 3,84 \mathrm{mil}\end{array}$ & 0,14 \\
\hline & 21 mar. 2020 & $\begin{array}{l}\text { Q: } 1,33 \mathrm{mil} \\
\mathrm{C}: 3,25 \mathrm{mil}\end{array}$ & 0,08 \\
\hline & 22 mar. 2020 & $\begin{array}{c}\text { Q: } 921 \\
\text { C: } 2,08 \text { mil }\end{array}$ & 0,23 \\
\hline \multirow{3}{*}{ Segundo período } & 23 mar. 2020 & $\begin{array}{c}\text { Q: } 849 \\
\mathrm{C}: 2,75 \mathrm{mil}\end{array}$ & 0,06 \\
\hline & 24 mar. 2020 & $\begin{array}{c}\text { Q: } 897 \\
\text { C: } 2,4 \text { mil }\end{array}$ & 0,32 \\
\hline & 25 mar. 2020 & $\begin{array}{l}\text { Q: } 1,36 \mathrm{mil} \\
\mathrm{C}: 4,6 \mathrm{mil}\end{array}$ & 0,08 \\
\hline \multirow{3}{*}{ Terceiro período } & 27 mar. 2020 & $\begin{array}{l}\text { Q: } 2,29 \mathrm{mil} \\
\text { C: } 4,08 \mathrm{mil}\end{array}$ & 0,15 \\
\hline & 28 mar. 2020 & $\begin{array}{l}\text { Q: } 1,43 \mathrm{mil} \\
\mathrm{C}: 2,34 \mathrm{mil}\end{array}$ & 0,23 \\
\hline & 29 mar. 2020 & $\begin{array}{c}\text { Q: } 947 \\
\text { C: } 2,62 \text { mil }\end{array}$ & 0,11 \\
\hline
\end{tabular}

Tabela 2. Dados divulgados pelo Covid19 Infodemic Observatory1 Períodos (conforme divisão de Recuero e Soares (2020)) Fonte: Covid19 Infodemic Observatory (2020)

Nota: (1) Na coluna Confiabilidade (em quantidade de tuítes), Q indica informações questionáveis e C indica informações confiáveis.

Ambos os estudos, porém, mostram que a infodemia é um fenômeno existente no Brasil no contexto do Twitter. É possível pensar que o método utilizado pelo Covid19 Infodemic Observatory não seja tão exato para a análise por não captar tanto as nuances do cenário brasileiro, na particularidade das buzzwords utilizadas no país. Exemplifica-se: o trabalho de Recuero e Soares (2020) utilizou como chave o termo "cura", que foi amplamente replicado nas mídias sociais após o pronunciamento do presidente; por sua vez, o observatório de De Domenico et al. (2020) não o fez.

As especificidades da infodemia no Brasil passam por termos, datas e condições específicas. Seria necessário um trabalho de campo mais abrangente, quanto ao espaço temporal e aos formatos de mídia; e contextualizado, quanto aos termos e variáveis examinados, para captar e analisar as nuances do desenrolar da infodemia na conjuntura brasileira. Observa-se que não há um estudo prospectivo como o de De Domenico et al. (2020) voltado para o Brasil, o que seria relevante para a compreensão mais completa de ainda mais facetas da infodemia no Brasil no âmbito do Twitter.

\section{CONCLUSÃO}

A pandemia e a infodemia são acontecimentos recentes. O cenário do qual os dados devem ser retirados, em verdade, ainda não foi formado, pois ambos os fenômenos ainda estão em curso. Dessa forma, é compreensível que não haja tantos trabalhos publicados a respeito deles, uma vez que o tempo da pesquisa científica não é imediato - especialmente se comparado ao tempo da informação ou mesmo ao tempo viral.

Em que pese a dificuldade de encontrar publicações conclusivas e passíveis de serem comparadas acerca da infodemia no Twitter, ou mesmo de preprints sobre o tema, é possível perceber que ela existe e tem implicações relevantes. Isso é patente ao considerar que as mídias sociais constituem ambiente propício para a circulação de des-informação, e que quanto mais exposição a informações falsas um indivíduo tiver, mais distorcida será sua percepção da pandemia e mais relapso será seu cumprimento das medidas de prevenção.

As informações problemáticas que compõem a infodemia, ao contrário do que pode se pensar, não podem ser todas classificadas como fake news. Ainda que essa definição careça de consenso na literatura, é possível compreender o termo como informações deliberadamente fabricadas com o objetivo de enganar os receptores das mensagens. Essa conceituação se adequa com um dos grupos de informação que compõem a desordem informacional, conforme proposta por Wardle e Derakhshan (2017, 2020), qual seja o dis-information. Os outros dois tipos de informação de acordo com os autores são mal-information, quando informações verdadeiras são propagadas na intenção de causar dano a outrem; e mis-information, quando ocorre um erro de interpretação ou de percepção que leva a erro.

A infodemia, por ser a abundância de informações sobre o tema, compõe-se de todos esses itens - além dos fatos verdadeiros, que, por serem divulgados repetidamente por meio de diversas fontes, acabam fazendo parte 
também do bombardeio de informações que atingem os indivíduos. Há casos de informações verdadeiras, mas mal interpretadas, que são repassadas tornando-se falsas; de informações falsas criadas com o objetivo de serem interpretadas como notadamente falsas, mas que acabam sendo lidas e repassadas como verdadeiras; e várias outras possibilidades.

Tanta informação, verdadeira ou falsa, acaba não informando de fato os usuários-cidadãos, mas sim desorientandoos e deixando-os falsamente cientes. Isso notadamente ocorre no Twitter, sendo que todos os estudos analisados verificaram a grande quantidade de tuítes acerca da COVID-19. Com efeito, a rede é um ambiente virtual em que muita informação é criada e disseminada, seja por humanos ou por bots, e tudo isso impacta os usuários.

O Brasil é um país que tem sofrido com a pandemia em grandes dimensões e, além da crise sanitária, a crise informacional também tem se feito presente. Pesquisas acerca da desordem informacional no Twitter e do desenvolvimento da infodemia em termos globais são importantes, e a inclusão do Brasil nessas análises ajuda a construir a compreensão do cenário brasileiro em meio a essa conjuntura.

Nada obstante, mais informações ainda são necessárias para uma análise profunda. Mostra-se relevante o desenvolvimento de mais pesquisas nacionais, em consonância com os acontecimentos locais e as peculiaridades do cenário brasileiro, para a consolidação da análise ou, pelo menos, da forma de coleta de dados, da infodemia no Brasil. A concentração de esforços nesse sentido é necessária para o combate à viralização - tanto no sentido comunicacional, de espalhamento rápido de informações pela Internet, quanto no sentido original, de espalhamento de vírus. 


\section{REFERÊNCIAS}

Allcott, H., \& Gentzkow, M. (2017). Social media and fake news in the 2016 election. Journal of economic perspectives, 31 (2), 21-36. doi: 10.1257/jep.31.2.211

Ball, P., \& Maxmen, A. (2020). The epic battle against coronavirus misinformation and conspiracy theories. Nature, 581 (7809), 371-374. doi: 10.1038/d41586-020-01452-Z

Bridgman, A., Merkley, E., Loewen, P. J., Owen, T., Ruths, D., Teichmann, L., \& Zhilin, O. (2020). The causes and consequences of covid-19 misperceptions: Understanding the role of news and social media. The Harvard Kennedy School (HKS) Misinformation Review, 1(esp), 1-18. doi: 10.37016/mr-2020-028

Briggs, A., \& Burke, P. (2006). Uma história social da mídia. Rio de Janeiro: Zahar.

Burroughs, W. (1994). A revolução eletrônica. Lisboa: Vega.

Cardoso, I. d. A. (2019). Propagação e influência de pós-verdade e fake news na opinião pública (Dissertação de Mestrado, Universidade de São Paulo). Recuperado de https://teses.usp.br/teses/disponiveis/27/27154/ tde-11112019-174743/pt-br.php

Castaldi, S., Maffeo, M., Rivieccio, B. A., Zignani, M., Manzi, G., Nicolussi, F., ... Biganzoli, E. (2020). Monitoring emergency calls and social networks for covid-19 surveillance. to learn for the future: The outbreak experience of the lombardia region in italy. Acta bio-medica: Atenei Parmensis, 91 (9-S), 29-33. doi: 10.23750/abm.v91i9S.10038

Castells, M. (1999). A sociedade em rede. São Paulo: Paz e Terra.

Cinelli, M., Quattrociocchi, W., Galeazzi, A., Valensise, C. M., Brugnoli, E., Schmidt, A. L., .. Scala, A. (2020). The covid-19 social media infodemic. Preprint. Recuperado de arXiv:2003.05004

Coelho, M. C. S. (2018). O surgimento de um novo paradoxo informacional a partir do uso dainformação em rede: interação e convivência social entre os sujeitos conectados (Monografia de Especialização, Universidade Federal de Minas Gerais, Brasil). Recuperado de http://hdl.handle.net/ 1843/BUOS-B5NKCQ

De Domenico, M., Gallotti, R., Sacco, P., Castaldo, N., \& Valle, F. (2020). Covid19. infodemics observatory. doi: 10.17605/OSF.IO/N6UPX

Dourado, T. M. S. G. (2019). Fake news na eleição presidencial de 2018 no brasil (Tese de Doutorado, Universidade Federal da Bahia, Brasil). Recuperado de http:// repositorio.ufba.br/ri/handle/ri/31967

Gabielkov, M., Ramachandran, A., Chaintreau, A., \& Legout, A. (2016). Social clicks: What and who gets read on twitter? In Proceedings of the $2016 \mathrm{acm}$ sigmetrics international conference on measurement and modeling of computer science (p. 179-192). Recuperado de https://hal.inria.fr/hal-01281190

Gil, A. C. (2008). Métodos e técnicas de pesquisa social. 6. ed. Ediitora Atlas SA.

Habermas, J. (2014). Mudanca estrutural da esfera pública: investigações sobre uma categoria da sociedade burguesa; com prefácio a edição de 1990. Ed. Unesp.

Han, B.-C. (2018). No enxame: perspectivas do digital. Editora Vozes Limitada.
Lancet Infectious Diseases. (2020). Editorial. The Lancet Infectious Diseases, 20(8), 875. Recuperado de 10.1016/ S1473-3099(20)30565-X.

Larson, H. J. (2020). A call to arms: helping family, friends and communities navigate the covid-19 infodemic. Nature Reviews Immunology, 20(8), 449-450. Recuperado de 10.1038/s41577-020-0380-8

Lazer, D. M., Baum, M. A., Benkler, Y., Berinsky, A. J., Greenhill, K. M., Menczer, F., .. Rothschild, D. (2018). The science of fake news. Science, 359(6380), 1094-1096. Recuperado de 10.1126/science.aao2998

Lévy, P. (1996). Que é o virtual?, o. Editora 34.

Lima, C. R. M. d., Sánchez-Tarragó, N., Moraes, D., Grings, L., Maia, M. R., et al. (2020). Emergência de saúde pública global por pandemia de covid-19: desinformação, assimetria de informações e validação discursiva. Folha de Rosto, 6(2), 5-21. Recuperado de 10.46902/2020n2p5-21

Marchiori, P. Z. (2002). A ciência e a gestão da informação: compatibilidades no espaço profissional. Ciência da informação, 31(2), 72-79. Recuperado de http://revista.ibict.br/ ciinf/article/view/962

McQuail, D., de Jesus, C., \& Ponte, C. (2003). Teoria da comunicação de massas. Lisboa: Fundação Calouste Gulbenkian.

Michaelis. (2020). Vírus. Dicionário Michaelis. Recuperado de http: $/ /$ michaelis.uol.com.br $/$ busca $? \mathrm{r}=0 \& \mathrm{f}=0 \& \mathrm{t}=$ 0\&palavra $=\mathrm{v} \% \mathrm{C} 3 \%$ ADrus

Newman, N., Fletcher, R., Kalogeropoulos, A., \& Nielsen, R. K. (2020). Reuters institute digital news report 2019. Dicionário Michaelis. Recuperado de http:// www.digitalnewsreport.org/survey/2019/

Okano, É. Y. (2020). Análise e caracterização de textos intencionalmente enganosos escritos em português usando métodos de processamento de textos (Dissertação de Mestrado, Universidade de São Paulo, Brasil). Recuperado de https://www.teses.usp.br/teses/disponiveis/59/59143/ tde-29062020-171001/pt-br.php

Organização Pan-Americana da Saúde. (2020). Entenda a infodemia e a desinformação na luta contra a covid-19. Recuperado de https://iris.paho.org/handle/10665.2/52054

Oxford Languages. (2020). Word of the year 2016. Oxford University Press. Recuperado de https://languages.oup .com/word-of-the-year/2016/

Persily, N. (2017). The 2016 us election: Can democracy survive the internet? Journal of democracy, 28(2), 63-76. Recuperado de 10.1353/jod.2017.0025

Pool, I. (1983). Technologies of freedom harvard university press. Cambridge.

Recuero, R., \& Soares, F. (2020). O discurso desinformativo sobre a cura do covid-19 no twitter. In E-compós. doi: $10.30962 /$ ec. 2127

Santos, A. (2008). Complexidade e transdisciplinaridade em educação: cinco princípios para resgatar o elo perdido. Revista brasileira de educação, 13(37), 71-83. Recuperado de https://www.scielo.br/pdf/rbedu/v13n37/07.pdf.

Sintra, M. C. D. (2019). Fake news e a desinformação: perspetivar comportamentos e estratégias informacionais (Tese de doutorado). Recuperado de http://hdl.handle.net/ $10362 / 79564$

Twitter. (2020a). Como retweetar. Autor. Recuperado de https://help.twitter.com/pt/using-twitter/how-to-retweet 
Twitter. (2020b). Sobre. Autor. Recuperado de https:// about.twitter.com/pt.html

Twitter Comms. (2020). More reading - people open articles $40 \%$ more often after seeing the prompt more informed tweeting - people opening articles before rting increased by 33\% some people didn't end up rting after opening the article - which is fine! some tweets are best left in drafts. Twitter. Recuperado de https://twitter.com/TwitterComms/status/ 1309178716988354561

Vosoughi, S., Roy, D., \& Aral, S. (2018). The spread of true and false news online. Science, 359(6380), 1146-1151. Recuperado de 10.1126/science.aap9559

Wardle, C., \& Derakhshan, H. (2017). Information disorder: Toward an interdisciplinary framework for research and policy making. Council of Europe report, 27. Recuperado de https://edoc.coe.int/en/media/ 7495-information-disorder-toward-an-interdisciplinary

-framework-for-research-and-policy-making.html

Wardle, C., \& Derakhshan, H. (2020). Thinking about "information disorder": formats of misinformation, disinformation, and mal-information. In Journalism, "fake news" $\mathcal{G}$ disinformation: Handbook for journalism education and training. Paris: United Nations Educational, Scientific and Cultural Organization. Recuperado de https://en.unesco.org/sites/default/files/journalism _fake_news_disinformation_print_friendly_0.pdf

Zarocostas, J. (2020). How to fight an infodemic. The Lancet, 395(10225), 676. Recuperado de 10.1016/S0140 -6736(20)30461-X

Silva, P. V. D. (2020). Pandemia e infodemia nas mídias: análise da desordem informacional no Twitter. AtoZ: novas práticas em informação e conhecimento, 9(2), 148 - 159. Recuperado de: http://dx.doi.org/10.5380/ atoz.v9i2.76506 